\title{
Conventional TENS Efficacy on Autonomic Function and MCV of the Neuropathic Tibial Nerve.
}

\author{
Z. Mowafy Emam Mowafy*, Wafaa H. Borhan * and Akef A. Khowailed** \\ * Physical Therapy Department for Surgery, Faculty of Physical Therapy, Cairo \\ University. Egypt. \\ ** Physiology Department Faculty of Medicine, Cairo University, Egypt.
}

\begin{abstract}
This study has been conducted to determine efficacy of conventional TENS on the autonomic function by assessing the big toe skin temperature (TST) and the motor conduction velocity $(\mathrm{MCV})$ of the neuropathic tibial nerve. Thirty neuropathic patients (20 males, and 10 females) ranging in age from 30 to 50 years $(X=45.41 \pm 1.16)$ who were divided into 3 groups of equal number (two study and one control) and consented to receive $40 \mathrm{~Hz}$ and $80 \mathrm{~Hz}$ conventional TENS along the tibial nerve course for the first and second study groups respectively, while the third (control group) received placebo TENS. Both TST and MCV were recorded before and immediately after treatment (one session for 25 minutes). Treatment and data collection procedures were done in air conditioned room with the ambient room temperature was adjusted within the comfortable zone between $24^{\circ} \mathrm{C}$ to $28^{\circ} \mathrm{C}$. Data collected showed a significant differences in both TST and MCV in meter/ second, in the first study group $(\mathrm{P}<0.05)$ and in the second study group $(\mathrm{p}<0.001)$. While there was no significant differences in the control group ( $p>0.05$ ). There was a correlation between the TST and MCV in both study and control groups. The $80 \mathrm{~Hz}$ conventional TENS was more fruitful in enhancing the autonomic and electrophysiological functions of the neuropathic tibial nerve as manifested by the increased TST and MCV than $40 \mathrm{~Hz}$ conventional TENS.
\end{abstract}

\section{Introduction:-}

Clinical electrophysiology began toward the end of the eighteenth century with Galvani's discovery of animal electricity, ${ }^{5.8 .12}$.

Electrophysiological assessments of muscle and nerve are now considered indispensable in the practice of neurology, physical therapy, and other related clinical disciplines, ${ }^{3.9 .11 .14 .25}$.

The clinical measurement of nerve conduction velocities has become increasingly popular since the late articles by Hodes et al. (1940 and 1948), which contained the first clinically relevant discussion of conduction velocity testing and created great interest in the subject of electrophysiological testing, ${ }^{1.7111 .15 .21}$.

Skin temperature assessment is one of the most important autonomic nerve functions as dominance of the sympathetic tone in many neurological disturbances as polyneuropathy lead to increased systemic vascular resistance, decreased cutaneous, muscular, and endoneurial blood flow resulting in nerve function alterations, ${ }^{18.20 .27}$.

Certain patients are more susceptible to a peripheral neuropathies as alcoholics, diabetics and others, as well as the old aged because they are less mobile, and their nerves do not tolerate pressure well, ${ }^{2.6 .28 .30}$.

Transcutaneous electrical nerve stimulation is an effective, noninvasive, non -aversive, non-addictive method of managing pain, muscle guarding and dysfunction of the pain cycle as well as the internal changes that accompanied the pain cycle can be managed or at least reduced by TENS application. As pain produces a state of muscle tension that results in a 
diminished blood supply within the painful area or (a state of ischemia), increased metabolites, decreased oxygen supply, and increased muscle fatigue, inflammation and edema, ${ }^{15.19 .24}$.

All these internal changes can lead to progressive amplification of the pain cycle which can be prevented or reduced by TENS, ${ }^{4 \cdot 10.13 .17}$.

\section{Material and Methods}

\section{Subjects:-}

Thirty patients (20males and 10 females) ranging in age from 30 to50 years, $(X=45.41 \pm 1.16)$ selected from the out clinics of Kasr -El -Aini (Cairo University Hospitals). They were divided randomly into 3 groups of equal number (two study and a control group). Patients were not familiar with the TENS techniques and consented to receive $40 \mathrm{~Hz}$ and $80 \mathrm{~Hz}$ of conventional TENS along the tibial nerve course for the first and second study groups respectively. While the third (control) group was received placebo TENS.

\section{Instrumentation:-}

\section{The Treatment Equipment}

In this study a dual channel TENS stimulator Model DH- 808, made by DAE HAN in Korea. The stimulation parameters and the principal characteristics of TENS were, $40 \mathrm{~Hz}$ for frequency, $150 \mu \mathrm{Sec}$ for the pulse width , $20 \mathrm{~mA}$ intensity for the first study group, $80 \mathrm{~Hz}$ for frequency, $150 \mu \mathrm{Sec}$ for the pulse width , $20 \mathrm{~mA}$ intensity for the second study group and placebo TENS for the third (control) group.

\section{The Measuring Equipment :-}

The Amplaid EMG12 electrodiagnostic machine, that made by (Amplaid S.P.A in Milan Italy) was utilized to obtain an objective evaluation of the tibial nerve MCV.

An electronic thermometer (Badr Telecom) number 6728085, model (RKIII) made in Japan, was used to obtain an objective recording of the big toe skin temperature(TST).

\section{Procedures:- \\ Evaluation ;-}

The study was conducted in an air conditioned room, where a thermometer was available during the whole time of the experiment between $24^{\circ} \mathrm{C}$ to $28^{\circ} \mathrm{C}$ by setting thermostat of the air condition and thus the temperature gradient along course of the tested nerve was minimized and the temperature - related variability was eliminated, ${ }^{31}$.

The MCV of the tibial nerve (medial planter nerve) was measured via the Amplaid EMG 12, where the active recording electrode was placed over the belly of the abductor hallucis (motor point of the abductor hallucis is located $1 \mathrm{~cm}$ behined and below the navicular tubercle on the medial aspect of the foot), ${ }^{22.23}$.

The reference electrode was placed distally on the tendon of the abductor hallucis and the ground electrode was placed between the active recording electrode and the distal stimulating electrodes, ${ }^{26.29}$.

The proximal stimulation was at the popiteal fossa while distal stimulation was done behined the medial malleolus $(8 \mathrm{~cm}$. from the active recording electrode), ${ }^{10.13}$.

\section{Treatment :-}

According the aforementioned stimulation parameters and characteristics of the conventional TENS, the dual channel TENS was used to administer the conventional TENS along the tibial nerve course with the patient supine, (hips slightly flexed, and laterally rotated, knee slightly flexed ( only 10 degrees) and slightly planter flexed ankles.

Two electrodes (from only one channel) were used, one electrode was positioned on the medial boundary of the popliteal fossa (positive electrode) while the other was positioned behind the medial malleolus (negative electrode), ${ }^{20.27}$.

\section{Data analysis:-}

One treatment session (25 minutes) was administered via TENS stimulator, and both the TST and MCV were measured before and immediately after treatment session. Collected data were fed into computer for 
the statistical analysis, descriptive statistics as mean, standard deviation, minimum, and maximum were calculated for each group.

The t-Test was done to compare between the 3 groups and within each group. Alpha point of 0.05 was used as level of significance, ${ }^{32}$.

\section{Results:-}

The Results of the TST Changes in the Three Groups:

As shown in the table (1) and figure (1), the mean value of the TST before treatment was $(28.25 \pm 2.3)^{\circ} \mathrm{C}$, in the first study group, while after treatment was $(29.8 \pm 2.43)^{\circ} \mathrm{C}$.

These results revealed a significant increase in TST $(\mathrm{P}<0.05)$. But in the second study group, the mean value of the TST, before treatment was $(28.7 \pm 2.34)^{\circ} \mathrm{C}$, While after treatment was $(31.60 \pm 2.57)^{\circ} \mathrm{C}$, and these revealed also a significant increase in the TST $(\mathrm{P}<0.05)$.

In the control group, the mean value of the TST before treatment was $(28.6 \pm 2.33)^{\circ} \mathrm{C}$, while after treatment was $(28.65 \pm 2.33)^{\circ} \mathrm{C}$ and revealed a non significant difference in the TST $(p>0.05)$.

\section{Results of the MCV Changes in the} Three Groups:-

As observed in table (2) and fig.(2), the mean value of the MCV before treatment was $(41.2 \pm 2.54) \mathrm{meter} / \mathrm{sec}$ in the first study group, while after treatment was (43.6 \pm 2.69$)$ meter $/ \mathrm{sec}$.

These results revealed a significant increase in MCV $(\mathrm{P}<0.05)$ and in the second study group the mean value of the MCV before treatment was $(42.3 \pm 2.61)$ meter /second while after treatment was $(46.3 \pm 2.85)$ meter $/ \mathrm{sec}$, these revealed a significant increase in the MCV $(\mathrm{P}<0.05)$.

In the control group the mean value of the MCV before treatment was (41.5 \pm 2.56$)$ meter $/ \mathrm{sec}$, while after treatment was (42.1 \pm 2.6$)$ meter /sec, and these results revealed a non significant differences in the $\operatorname{MCV}(\mathrm{P}>0.05)$.
Table (1): The mean values of TST before and after treatment in the three groups.

\begin{tabular}{|c|c|c|c|c|c|c|}
\hline \multirow{2}{*}{} & \multicolumn{2}{|c|}{$\begin{array}{c}\text { First } \\
\text { Experiment } \\
\text { al group }\end{array}$} & \multicolumn{2}{c|}{$\begin{array}{c}\text { Second } \\
\text { Experimental } \\
\text { group }\end{array}$} & \multicolumn{2}{|c|}{$\begin{array}{c}\text { Control } \\
\text { group }\end{array}$} \\
\cline { 2 - 7 } & $\begin{array}{c}\text { Pre- } \\
\text { TTT }\end{array}$ & $\begin{array}{c}\text { Pos- } \\
\text { TT } \\
\text { T }\end{array}$ & $\begin{array}{c}\text { Pre- } \\
\text { TTT }\end{array}$ & $\begin{array}{c}\text { Post- } \\
\text { TTT }\end{array}$ & $\begin{array}{c}\text { Pre- } \\
\text { TTT }\end{array}$ & $\begin{array}{c}\text { Post- } \\
\text { TTT }\end{array}$ \\
\hline X & $\begin{array}{c}28.2 \\
5\end{array}$ & 29.8 & 28.7 & 31.6 & 28.6 & 28.65 \\
\hline SD & 2.3 & 2.43 & 2.34 & 2.57 & 2.333 & 2.337 \\
\hline $\begin{array}{c}\text { P. } \\
\text { Value }\end{array}$ & $<0.05$ & 0.001 & \multicolumn{2}{|c|}{$>0.05$} \\
\hline $\begin{array}{c}\text { Level } \\
\text { of Sig. }\end{array}$ & \multicolumn{2}{|c|}{$\mathrm{S}$} & \multicolumn{2}{|c|}{$\mathrm{S}$} & \multicolumn{2}{|c|}{ NS } \\
\hline
\end{tabular}

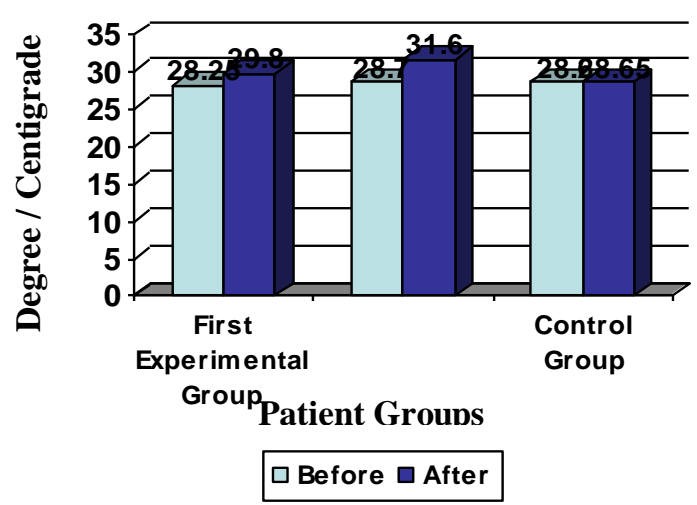

Fig. (1): Mean values of TST in ${ }^{\circ} \mathrm{C}$ before and after treatment for the 3 groups.

Table (2): The mean values of MCV before and after treatment in the three groups.

\begin{tabular}{|c|c|c|c|c|c|c|}
\hline & \multicolumn{2}{|c|}{$\begin{array}{c}\text { First } \\
\text { Experimenta } \\
1 \text { group }\end{array}$} & \multicolumn{2}{|c|}{$\begin{array}{c}\text { Second } \\
\text { Experime } \\
\text { ntal group }\end{array}$} & \multicolumn{2}{|c|}{$\begin{array}{c}\text { Control } \\
\text { group }\end{array}$} \\
\hline & $\begin{array}{l}\text { Pre- } \\
\text { TTT }\end{array}$ & $\begin{array}{c}\text { Pos } \\
- \\
\text { TT } \\
\text { T }\end{array}$ & $\begin{array}{c}\text { Pre } \\
- \\
\text { TT } \\
\text { T }\end{array}$ & $\begin{array}{c}\text { Pos } \\
\text { t- } \\
\text { TT } \\
\text { T }\end{array}$ & $\begin{array}{c}\text { Pre } \\
- \\
\text { TT } \\
\text { T }\end{array}$ & $\begin{array}{c}\text { Post } \\
- \\
\text { TT } \\
\text { T }\end{array}$ \\
\hline$X$ & 41.2 & $\begin{array}{c}43 . \\
6\end{array}$ & $\begin{array}{c}42 . \\
3\end{array}$ & $\begin{array}{c}46 . \\
3\end{array}$ & $\begin{array}{c}41 . \\
5\end{array}$ & 42.1 \\
\hline SD & 2.54 & $\begin{array}{c}2.6 \\
9\end{array}$ & $\begin{array}{c}2.6 \\
1\end{array}$ & $\begin{array}{c}2.8 \\
5\end{array}$ & $\begin{array}{c}2.5 \\
6\end{array}$ & 2.6 \\
\hline $\begin{array}{c}\mathrm{P} . \\
\text { Value }\end{array}$ & \multicolumn{2}{|c|}{$<0.05$} & \multicolumn{2}{|c|}{0.001} & \multicolumn{2}{|c|}{$>0.05$} \\
\hline $\begin{array}{c}\text { Level of } \\
\text { Sig. }\end{array}$ & \multicolumn{2}{|c|}{$\mathrm{S}$} & \multicolumn{2}{|c|}{$\mathrm{S}$} & \multicolumn{2}{|c|}{ NS } \\
\hline
\end{tabular}




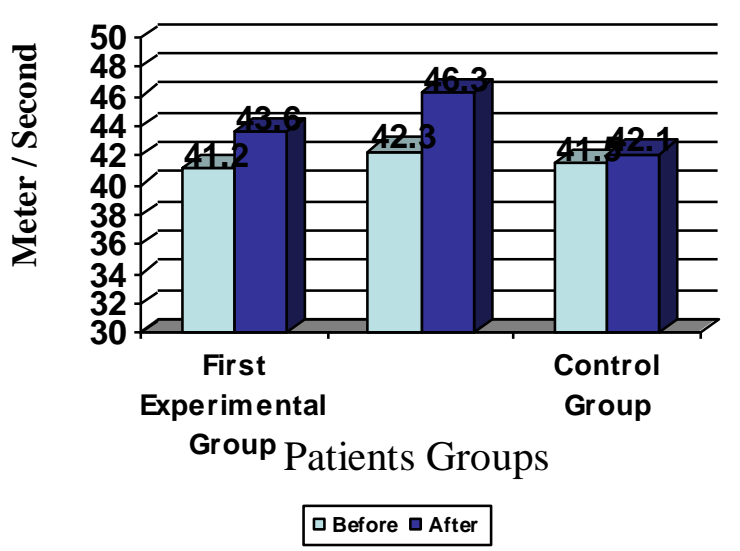

Fig. (2): Mean values of MCV in meter/second before and treatment for the 3 groups.

\section{Discussion}

It is better to use the term (neuropathy) than neuritis as the pathological lesion is degenerative and not always inflammatory, ${ }^{11.14 .22}$.

Diabetes mellitus can be considered as the most common metabolic disorder with substantial neurological complications, any involvement of the peripheral nervous system in diabetes mellitus is referred as diabetic neuropathy.

Also peripheral neuropathy is a common complication in patients with chronic renal failure. Motor manifestation of neuropathies are muscle weakness or paralysis of the lower motor neuron nature in the form of wasting, hypotonia and hyporflexia. Weakness in polyneuropathy is bilateral, symmetrical affecting lower limbs more than upper limbs, affecting distal muscles more than proximal muscles, and affecting extensors more than flexors, ${ }^{18.27 .30}$.

Sensory manifestations are pain, parasthesia, and sensory impairment of stock and glove nature, while the autonomic manifestations are vasomotor in the form of coldness and cyanosis or cutaneous in the form of loss of hair, brittle nails, and trophic ulcers, ${ }^{7.9 .13 .15}$.

The findings of the present study showed no significant difference in the pretreatment records of the TST and MCV, between the mean values of the first and second study groups, between the mean values of the first study and control group as well as between the mean values of the second study and control group.

To avoid the possible implication of the placebo response, results of the control group were compared with each other and showed non-significant difference in both TST and MCV before and after treatment.

Results of this study revealed a significant increase in the mean values of both TST and MCV of the first study group after application of the $40 \mathrm{~Hz}$ conventional TENS , where TST(2) compared with the mean value of TST (1) as well as $\operatorname{MCV}(2)$ compared with the mean value of MCV(1).

Also results of this study revealed a significant increase in the mean values of both TST and MCV of the second study group after application of $80 \mathrm{~Hz}$ conventional TENS, where TST(2) compared with the mean value of TST (1), as well as $\mathrm{MCV}(2)$ compared with the mean value of $\mathrm{MCV}(1)$.

Significant differences showed in this study, were consistent with those observed and recorded by Kadda et al, 1991; Walsh et al, 1995; Roja et al, 1994; Long et al, 1991; and Mowafy et al, 1997.

Both the $40 \mathrm{~Hz}$ and $80 \mathrm{~Hz}$ conventional TENS produce sympathetic inhibition resulting in improving the peripheral circulation via lowering vascular resistance and increasing skin, muscle and nerve circulation as manifested by the increased TST and MCV.

Both $40 \mathrm{~Hz}$ and $80 \mathrm{~Hz}$. Conventional TENS were effective in improving the autonomic and electrophysiological function as evident by the increased TST and MCV.

\section{Conclusion}

Pain control should not remain the only indication for TENS application. The $80 \mathrm{~Hz}$ conventional TENS was more fruitful than $40 \mathrm{~Hz}$ conventional TENS in enhancing the autonomic and electrophysiological functions of the nerve as reflected by the increased TST and MCV. 


\section{References:}

1. Abram, S.E.; Asiddo, C.B. and Reynolds, A.C.: Increased skin temperature during TENS. Anesth. Analg. Cleve. 99:22. 1980.

2. Adams, R.D. and Victor, M.D.: Principles of neurology, McGraw-Hill, New York, pp 1009-1077, 1989.

3. Albers, J.W. and Kelly, J.J.: Acquired inflammatory demyelinating polyneuropathies: Clinical and electrodiagnostic features. Muscle. Nerve. 12:435-451, 1989.

4. Aminof, M.J. : EMG in clinical practice. Addision - Wesley. New Jersey. 1978.

5. Aminoff, M.J.: Electrodiagnosis in clinical neurology. Churchill Livingstone, New York, 1980,

6. Anastakis, D.J.; Peters, W.J. and Lee, K.C.: Severe peripheral burn polyneuropathy. Burns. Therm. Inj. 12:232-235, 1987.

7. Andersson, D.A. and Holmgren, E. : Analegisc effect of peripheral conditioning stimulation. III. Effect of high frequency stimulation; segmental mechanisms interacting with pain. Acupunct. Electrother. Res. 3:23, 1978.

8. Andersson, S.A. : Pain control by sensory stimulation : Second world congress on pain. Montreal. Canada. Pain Abstracts. 1:97, 1978.

9. August, P.J. : Iatrogenic skin disease. Practitoner 224:471-478, 1980.

10. Augustinssion, L.E.; Bohlin, P. and Bundsen, P. : Pain relief during delivery by TENS. Pain 4:59, 1977.

11. Ballantyne, J.P. and Campbell, M.J. : Electrophysiological study after surgical repair of sectioned human peripheral nerves. J. Neurol. Neurosurg. Psychiatry. 36:797, 1973.

12. Basmajian, J.V. : Muscles alive: Their functions revealed by EMG. $4^{\text {th }}$ (ed). Williams \& Wilkins. Baltimore, 1978.

13. Bates, J.A. and Nathan, P.W. : TENS for chronic pain., Anaesthesia. 35:817, 1980.

14. Benecke, R. and Conrad, B. : The distal sensory nerve action potential as a diagnostic tool for the differentiation of lesions in dorsal roots and peripheral nerves. Neurology. 223:231, 1980.

15. Besson, J.M,. and Chaouch, A. : Peripheral and spinal mechanisms of nociception. Physiol. Rev. 67:67-186, 1989.

16. Bischko, J.J. : Acupuncture \& electrotherapeutics. Res. Int. J.5: 29, 1980.

17. Bolton, C.F., Gilbert, J.J.; Hahn, A.F. and Sbbald, W.J. : Polyneuropathy in critically ill patients. J. Neurol. Neurosurg. Psychiatry. 47:1223-1231, 1984.
18. Bowsher, D. : Central pain mechanisms \& modulation of Nociceptive input. In pain management \& control in physiotherapy. Wells, P.E. \& Frampton, V. (eds). Heinemman. London, 1988.

19. Braddley, W.G. : Disorders of peripheral nerve. Black Well. Oxford. 1974.

20. Bromage, P.R.; Camporesi, E. and Chestnut, D. : Epidural narcotics for postoperative Analgesia. Anaesthesia. Cleve 59:473-480, 1980.

21. Brzier, M.A. : The emergence of electrophysiology as an aid to neurology. In Aminoff, M.J. (Ed): Electrodiagnosis in clinical neurology. Churchill Livingstone. New York, 1980.

22. Buchthal, F.; Rosenfalck, A. and Trojaborg, T. : Electrophysiological findings in entrapment of the median nerve at the wrist and elbow. J. Neurol. Neurosurg. Psychiatry. 37:340, 1974.

23. Campbell, J.M. and Taub, A. : Local analgesia from percutaneous electrical stimulation. Arch. Neuro. 28:347, 1973.

24. Campell, J.M.; Raja, S.N. and Cohen, R.H. : Peripheral neural mechanism of nociception. Physiol. Rev. 85:87-89, 1989.

25. Cheng, R.S. and Pomeranz, B : Electroacupuncture analgesia could be mediated by at least two pain relieving mechanisms endorphin \& non-endorphin systems. Life. Sci. 26:631. 1980.

26. Chung, S.H. and Dickenson, A.H. : Pain, enkephalin \& Acupuncture, Nature, 283344, 1980.

27. Cox, P.D.; Kramer, J.F. and Hartsell, H. : Effect of different TENS stimulus parameters on ulnar motor nerve conduction velocity. Am. J. Phys., Med. Rehabil. 72 (5): 294-300, 1993.

28. Cronblath, D.R.; Corse, A.M. and Chaudhry, V. : Multifocal motor neuropathy: Response to immune globulin. Ann. Neuro. 33:237-242, 1993.

29. Dawson, D.M; Hallett, M. and Millender, L.H. : Entrapment Neuropathies. Proc. R. Soc. Med. 59:989, 1983.

30. Delisa, J.A.; Mackenzie, K. and Baran, E.M. : Manual of nerve conduction velocity and somatosensory evoked potentials. ( $2^{\text {nd }}$ ed.) New York. Raven press, 1987.

31. Mowafy, Z.E. : Effect of TENS on pain and autonomic nervous system of burned patients. Master Thesis, Cairo University, pp. 135, 1993.

32. Pipkin, F.B. : Medical statistics made easy. Edinbrugh. London. Melbourne and New York, 1984. 


\section{فاعلية التنبية العصبى الكهربى التقليدى عبر الجلا على الوظيفة التلقائية وسرعة التوصيل للألياف الحركية لعصب القصبة المُعتل}

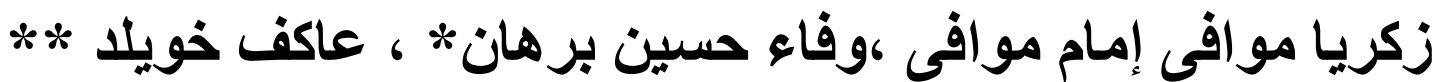

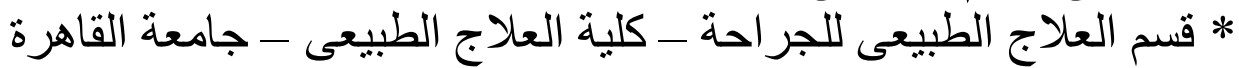

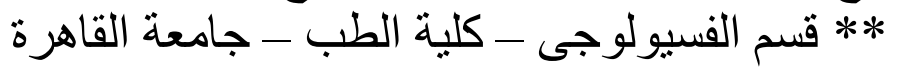

أجريت هذه الدر اسة لتحديد فاعلية التنبيه العصبى الكهربى التقليدى عبر الجلد

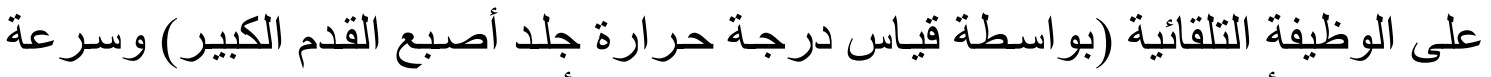

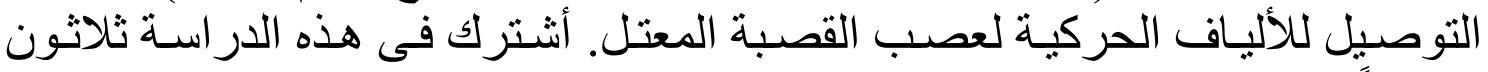

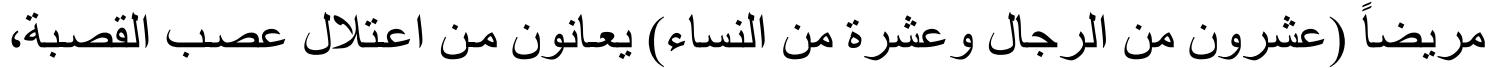

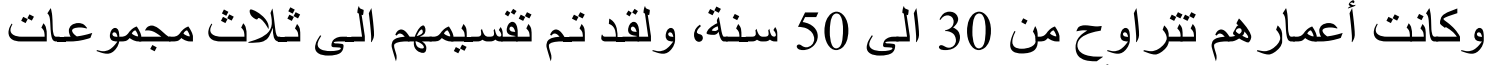

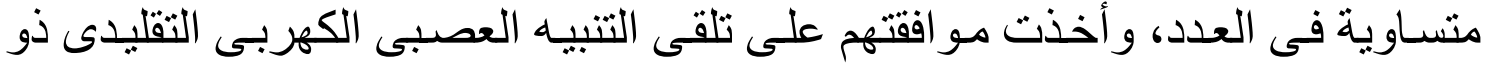

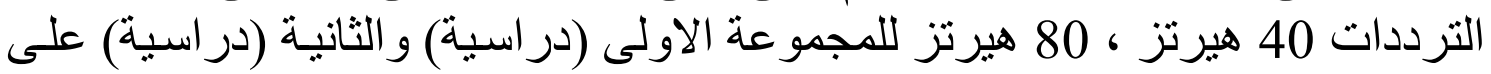

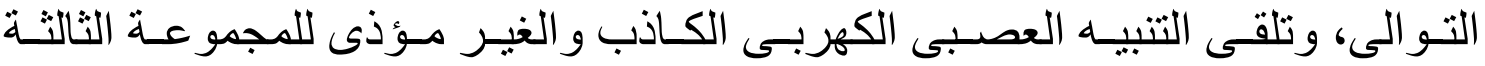

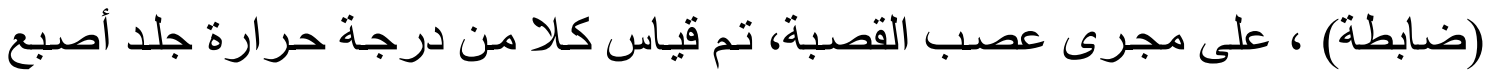

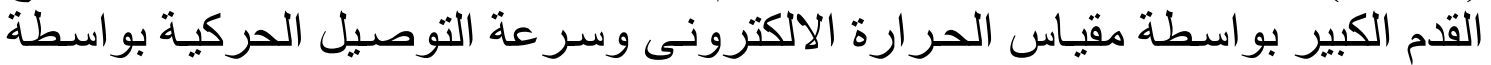

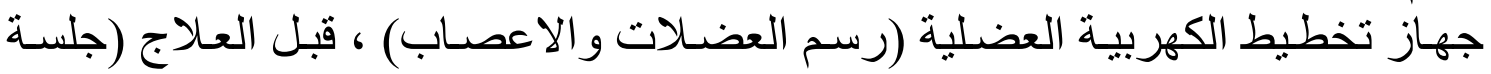

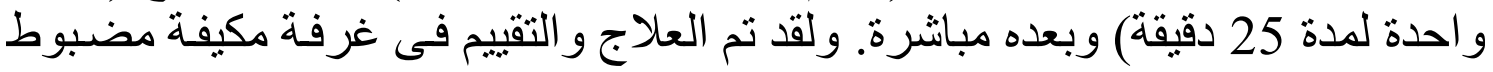

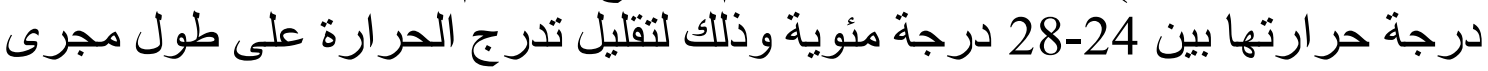

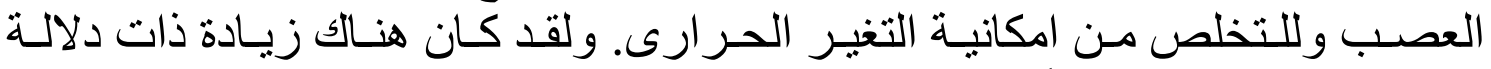

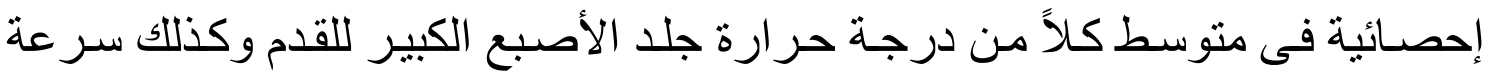

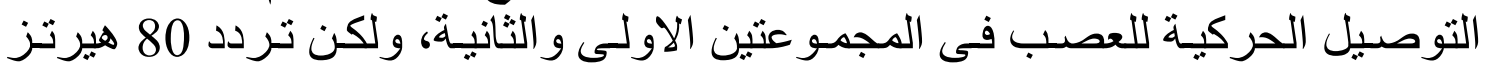

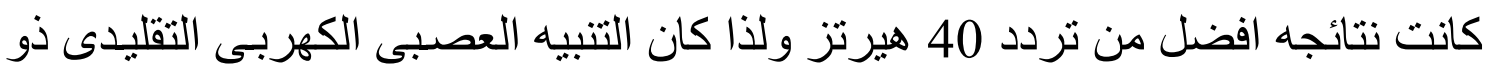

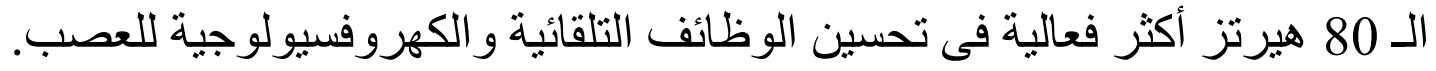

